\title{
Preparation and characterization of thermoplastic starch/polylactide blends with palmitic acid
}

\author{
$\underline{\text { Justyna Ostrowska }^{1}, \text { Magdalena Paluch }^{2}, \text { Karolina Sołtan }^{3}, \text { Waldemar Sadurski }}{ }^{4}$, Piotr Tyński $^{5}$
}

1. Organic Technologies Department, Łukasiewicz Research Network - New Chemical Syntheses Institute, POLAND, 24-110 Puławy, Al. Tysiąclecia Państwa Polskiego 13A, E-mail:

justyna.ostrowska@ins.lukasiewicz.gov.pl

2. Organic Technologies Department, Łukasiewicz Research Network - New Chemical Syntheses Institute, POLAND, 24-110 Puławy, Al. Tysiąclecia Państwa Polskiego 13A, E-mail: magdalena.paluch@ins.lukasiewicz.gov.pl

3. Organic Technologies Department, Łukasiewicz Research Network - New Chemical Syntheses Institute, POLAND, 24-110 Puławy, Al. Tysiąclecia Państwa Polskiego 13A, E-mail: karolina.soltan@ins.lukasiewicz.gov.pl

4. Organic Technologies Department, Łukasiewicz Research Network - New Chemical Syntheses Institute, POLAND, 24-110 Puławy, Al. Tysiąclecia Państwa Polskiego 13A, E-mail: waldemar.sadurski@ins.lukasiewicz.gov.pl

5. Organic Technologies Department, Łukasiewicz Research Network - New Chemical Syntheses Institute, POLAND, 24-110 Puławy, Al. Tysiąclecia Państwa Polskiego 13A, E-mail: piotr.tynski@ins.lukasiewicz.gov.pl

The effect of palmitic acid on the thermoplastic starch (TPS)/polylactide (PLA) blends was presented. TPS/PLA granulates were prepared during extrusion process. The TPS/PLA blends modified by fatty acid were analyzed by different methods to determine thermal, structural and rheological properties. The influence of acid on the blends plasticization was discussed.

Keywords - thermoplastic starch, polylactide, palmitic acid, plasticization, rheological properties

\section{Introduction}

Synthetic polymers produced from petrochemicals dominate the packaging market due to their low production costs, a well-known technology and a wide range of applications. However, the environmental problems related to the fact that petrochemical polymer waste is not biodegradable and the growing concern about the consequence of using these materials have inspired the research development on biodegradable polymer materials [1,2].

Currently, the two most popular biodegradable polymers made from natural and renewable raw materials are thermoplastic starch (TPS) and polylactide (PLA).

Native starch is a glucose polymer in which the monosaccharide units are linked by the $1,4^{\prime}$ - $\alpha$-glycosidic bonds. Starch can be separated into two fractions: insoluble in cold water called amylose and a fraction that dissolves in cold water called amylopectin. Amylose is a linear polymer which constitutes about $20 \%$ by weight of starch. Amylopectin is a highly branched molecules constitutes the remaining $80 \%$ of starch by weight and exhibits 1,6'- $\alpha$-glycosidic branches in its structure. Their structures are shown in Figure 1 [3].

Semicrystalline starch can be transformed into a fully amorphous material in the extrusion process at the temperature higher than $70^{\circ} \mathrm{C}$, under the influence of shear forces and in the presence of plasticizers. Thus, the produced material is known as thermoplastic starch (TPS). Unfortunately, thermoplastic starch - based products have high water vapor permeability and poor mechanical properties depending on changing humidity conditions. One of the known method regarding the improvement of the TPS properties is blending of thermoplastic starch with high-strength polyesters [4]. 

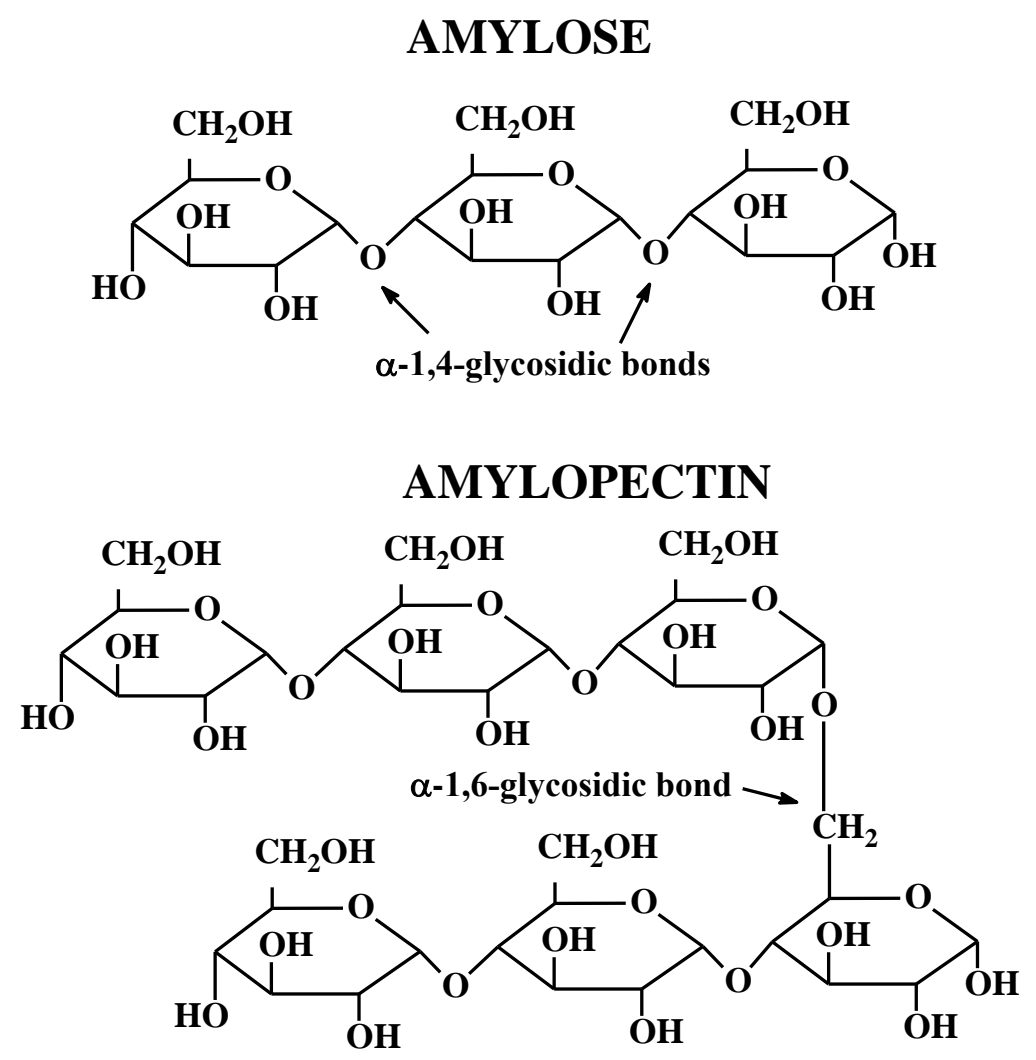

Fig.1. Structure of amylose and amylopectin.

Polylactide (Fig. 2) is a biodegradable aliphatic polyester obtained from L- and D-lactic acid. The PLA structure differs depending on the ratio of L- and D-lactide, offering different degrees of crystallinity, melting point as well as mechanical, rheological and barrier properties. PLA is a thermoplastic polymer in many ways similar to poly(ethylene terephthalate) (PET) and polystyrene (PS). It is highly transparent, rigid and brittle polymer. It has a relatively low rate of crystallization, which makes it a promising candidate for the fabrication of biaxially oriented films, thermoformed containers and stretch-blown bottles [5,6].<smiles>CC(C)OC(=O)C(C)(C)O</smiles>

Fig.2. PLA structure.

The combination of TPS and PLA is an effective way to reduce the price of the final product and improve the usable properties of starch materials [7]. The strategy of producing TPS/PLA blends has been used to decrease the dependence on the relative humidity and increase mechanical properties. A difficulty encountered in the production TPS/PLA polymer compositions results from the incompatibility of the two polymers. PLA is a hydrophobic polyester and TPS is hydrophilic, respectively. To enhance the interfacial adhesion between two polymers, a compatibilizing agent, such as maleic anhydride, diisocyanates or organic acid, may be added in the reactive extrusion process. The esterification with fatty acids makes it possible to obtain more hydrophobic starch esters [8,9]. 
In this study, the effect of palmitic acid $\left[\mathrm{CH}_{3}\left(\mathrm{CH}_{2}\right)_{13} \mathrm{CH}_{2} \mathrm{COOH}\right]$ on the TPS/PLA (50/50) blend properties was determined. For this purpose, reactive extrusion with saturated fatty acid was carried out and its activity as a plasticizer and compatibilizer was discussed.

\section{Materials and methods}

\section{Materials}

Native potato starch was purchased from Przedsiębiorstwo Przemysłu Ziemniaczanego Niechlów (Poland). Polylactide (PLA Ingeo TM Biopolymer 2003D) was supplied by NatureWorks (USA). Glycerol (99,5\% purity) was purchased from Brentag (Poland). Palmitic acid ( $\geq 99 \%$ purity) was obtained from Sigma-Aldrich.

\section{TPS/PLA blends preparation}

The TPS/PLA blends were prepared in a two-step extrusion process. In the first stage, the thermoplastic starch (TPS) was obtained. The potato starch and glycerol were premixed using a high speed mixer (Labtech Engineering, Thailand). The concentration of glycerol as a main plasticizer was $30 \mathrm{wt} . \%$ on starch dry weight. Palmitic acid (PA) was added to the starch/glycerol mixture and mixed again. The levels of palmitic acid in the mixture were $0.5 \mathrm{wt} . \%, 1 \mathrm{wt} . \%$ and $3 \mathrm{wt} . \%$, respectively. Glycerol-starch mixture with fatty acid were processed using co-rotating twin-screw extruder (Labtech Engineering, Thailand) with screw diameter $\mathrm{D}=20 \mathrm{~mm}$ with $\mathrm{L}: \mathrm{D}$ ratio $48: 1$ using barrel temperature in the range $70{ }^{\circ} \mathrm{C}-150{ }^{\circ} \mathrm{C}$ and at $120 \mathrm{rpm}$ screw speed.

Then, the obtained thermoplastic starch pellets were hand mixed with polylactide in $50 \mathrm{wt} . \% / 50 \mathrm{wt} . \%$ ratio and extruded again in the second step in the temperature range of $160{ }^{\circ} \mathrm{C}$ $-180{ }^{\circ} \mathrm{C}$ to produce a blends in the granulate form. Additionally, pure polylactide with palmitic acid in amount of $0.5 \mathrm{wt} . \%$ and $3 \mathrm{wt} . \%$ were processed to compare the properties of PLA in blends.

\section{Infrared spectrum (IR)}

FTIR spectra in the range of $4000-700 \mathrm{~cm}^{-1}$ were recorded by attenuated total reflection (ATR) method on a Nicolet iS10 Spectrum Scanner (Thermo Scientific, USA) over 32 consecutive scans with a resolution of $4 \mathrm{~cm}^{-1}$ at room temperature.

\section{Differential Scanning Calorimetry (DSC)}

The DSC measurements were performed using a TA Instruments Model Q20. The samples were heated and cooled from $-90{ }^{\circ} \mathrm{C}$ to $180{ }^{\circ} \mathrm{C}$ in a nitrogen atmosphere at a rate of $10{ }^{\circ} \mathrm{C} / \mathrm{min}$.

\section{Rheological properties}

Mass Flow Rate (MFR) and Melt Volume Rate (MVR) were measured using a plastometer CEAST MF20 (Instron Ceast, Italy). The measurements were carried out at $190{ }^{\circ} \mathrm{C}$ and $200{ }^{\circ} \mathrm{C}$ with a mass of $2.16 \mathrm{~kg}$ according to ISO 1133.

The twin-bore capillary rheometer (Smart Rheo 50, Instron Ceast, Italy) was used to the assessment of the rheological properties of the produced granules. The viscosity values were measured in the following points of shear rate: 100, 200, 300, 500, 700, 900, 1100, 1400, 1700, 2000,2500 and $3000 \mathrm{~s}^{-1}$. The preheating time was equal to $300 \mathrm{~s}$. The measurements were carried out at 160 and $170{ }^{\circ} \mathrm{C}$ and two capillary dies (L/D = 30 and 5) were used. The real values of shear rate, shear stress and viscosity were calculated by applying the Rabinowitsch and the Bagley corrections. 


\section{Results and discussion}

\section{FTIR (ATR) Spectroscopy}

Fig. 3 shows the FTIR spectra of neat polylactide and TPS/PLA (50/50) blends with or without palmitic acid. PLA has a strong carboxyl stretching absorption at about $1750 \mathrm{~cm}^{-1}$. The band does not shift in TPS/PLA blends. Furthermore, there is no additional peaks exhibit when palmitic acid is included into the blend. However, some differences in the wavenumber ranges from $1000 \mathrm{~cm}^{-1}$ to $1150 \mathrm{~cm}^{-1}$ were observed. The peak at $1024 \mathrm{~cm}^{-1}$ in TPS/PLA blend is attributed to the stretching vibration of $\mathrm{C}-\mathrm{O}$ in $\mathrm{C}-\mathrm{O}-\mathrm{C}$ [10]. The intensity of this peak decreases as the PA content increases, suggesting that acid hydrolysis reaction of the glycosidic linkages has occurred. The interaction between palmitic acid and starch/glycerol mixture was observed during the preparation of thermoplastic starch (Fig. 4). The peak at $1700 \mathrm{~cm}^{-1}$ is attributed to the $\mathrm{C}=\mathrm{O}$ stretching vibration in carboxyl group of pure palmitic acid. A new absorption band occurring at about $1734 \mathrm{~cm}^{-1}$ could be result of an esterification reactions between palmitic acid and starch or glycerol which occurred during the reactive extrusion. Due to the presence of ester linkages in a similar range of wavenumber as for in PLA, these linkages can be overlapped, it is difficult to observe these new ester linkages in spectra of TPS/PLA compositions.

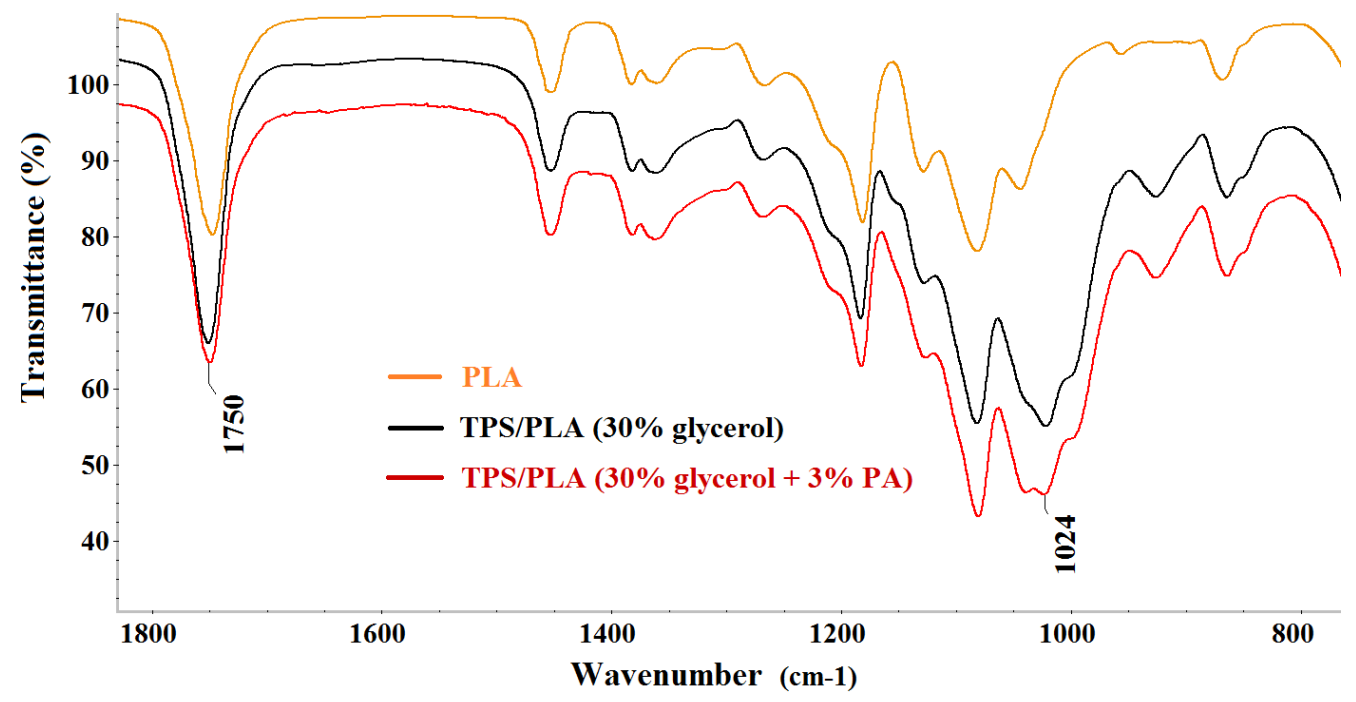

Fig.3. FTIR spectra of TPS/PLA blends.

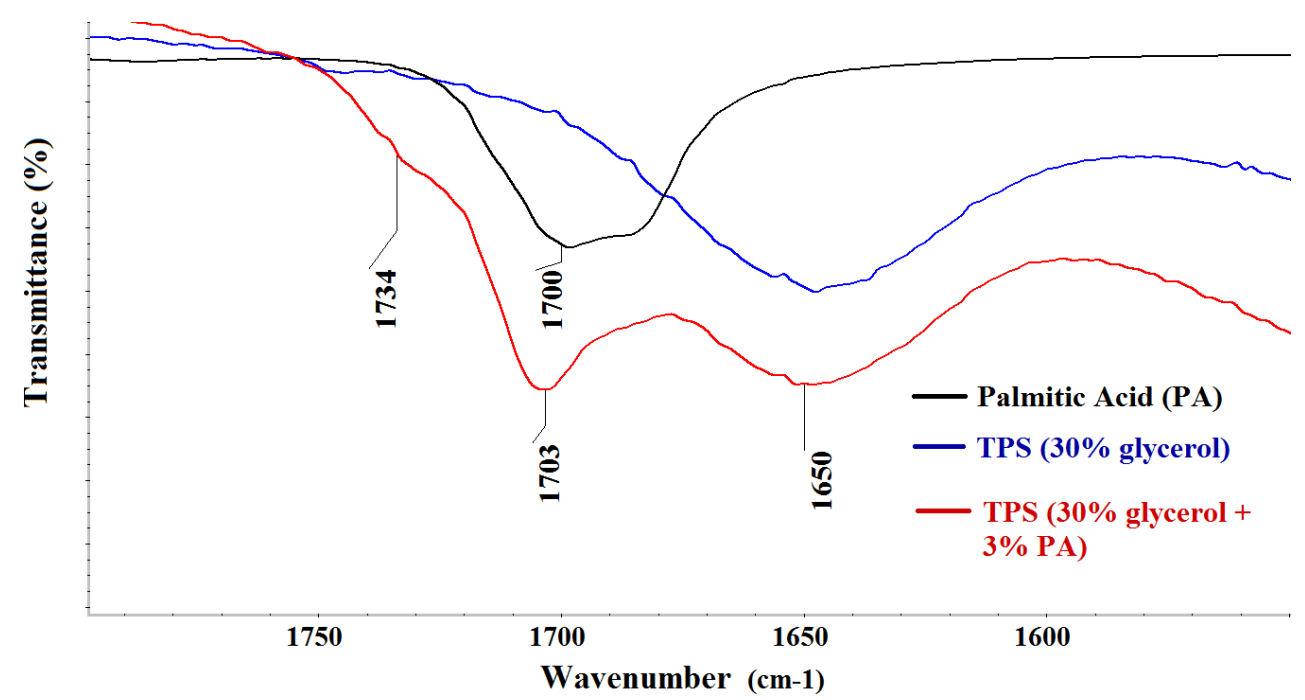

Fig.4. FTIR spectra $\left(1800 \mathrm{~cm}^{-1}-1500 \mathrm{~cm}^{-1}\right.$ range $)$ of thermoplastic starch with and without palmitic acid. 


\section{Thermal properties}

The DSC thermograms of PLA and PLA/TPS composites are shown in Figs. 5 and 6, respectively. The corresponding glass transition temperatures $\left(\mathrm{T}_{\mathrm{g}}\right)$, cold crystallization temperatures $\left(\mathrm{T}_{\mathrm{cc}}\right)$, and melting points $\left(\mathrm{T}_{\mathrm{m}}\right)$ of PLA compositions are reported in Table 1. After added the palmitic acid (PA) in amount $3 \mathrm{wt} . \%$, the $\mathrm{T}_{\mathrm{g}}$ of the TPS/PLA blends decreased by ca. $3^{\circ}$ and two obvious melting peaks of PLA was observed. The cold crystallization temperatures of the TPS/PLA blends decreased with a increasing an amount of PA. Changes in $\mathrm{T}_{\mathrm{g}}, \mathrm{T}_{\mathrm{cc}}$ and $\mathrm{T}_{\mathrm{m}}$ of PLA after adding fatty acid indicate interaction between the PLA chain and PA. These types of changes in thermograms are observed when the polymer plasticization process takes place.

Table 1 DSC data for neat PLA, PLA with palmitic acid and TPS/PLA blends

\begin{tabular}{|c|c|c|c|}
\hline PLA and its blends & $\mathbf{T}_{\mathbf{g}}\left[{ }^{\circ} \mathbf{C}\right]^{\mathbf{1})}$ & $\mathbf{T}_{\mathbf{c c}}\left[{ }^{\circ} \mathbf{C}^{\mathbf{2})}\right.$ & $\mathbf{T}_{\mathbf{m}}\left[{ }^{\circ} \mathbf{C}\right]^{\mathbf{3}}$ \\
\hline neat PLA & & & \\
\hline PLA + 0,5\% PA & 58 & 117 & 150 \\
\hline PLA + 3\% PA & 54 & 103 & 145,151 \\
\hline TPS/PLA & 58 & - & 148 \\
\hline TPS/PLA + 0,5\% PA & 59 & - & 148 \\
\hline TPS/PLA + 1\% PA & 60 & 113 & 147 \\
\hline TPS/PLA + 3\% PA & 56 & 108 & 145 \\
\hline
\end{tabular}

1) $2^{\text {nd }}$ heating cycle, ${ }^{2)} 1^{\text {st }}$ heating cycle, ${ }^{3)} 1^{\text {st }}$ heating cycle
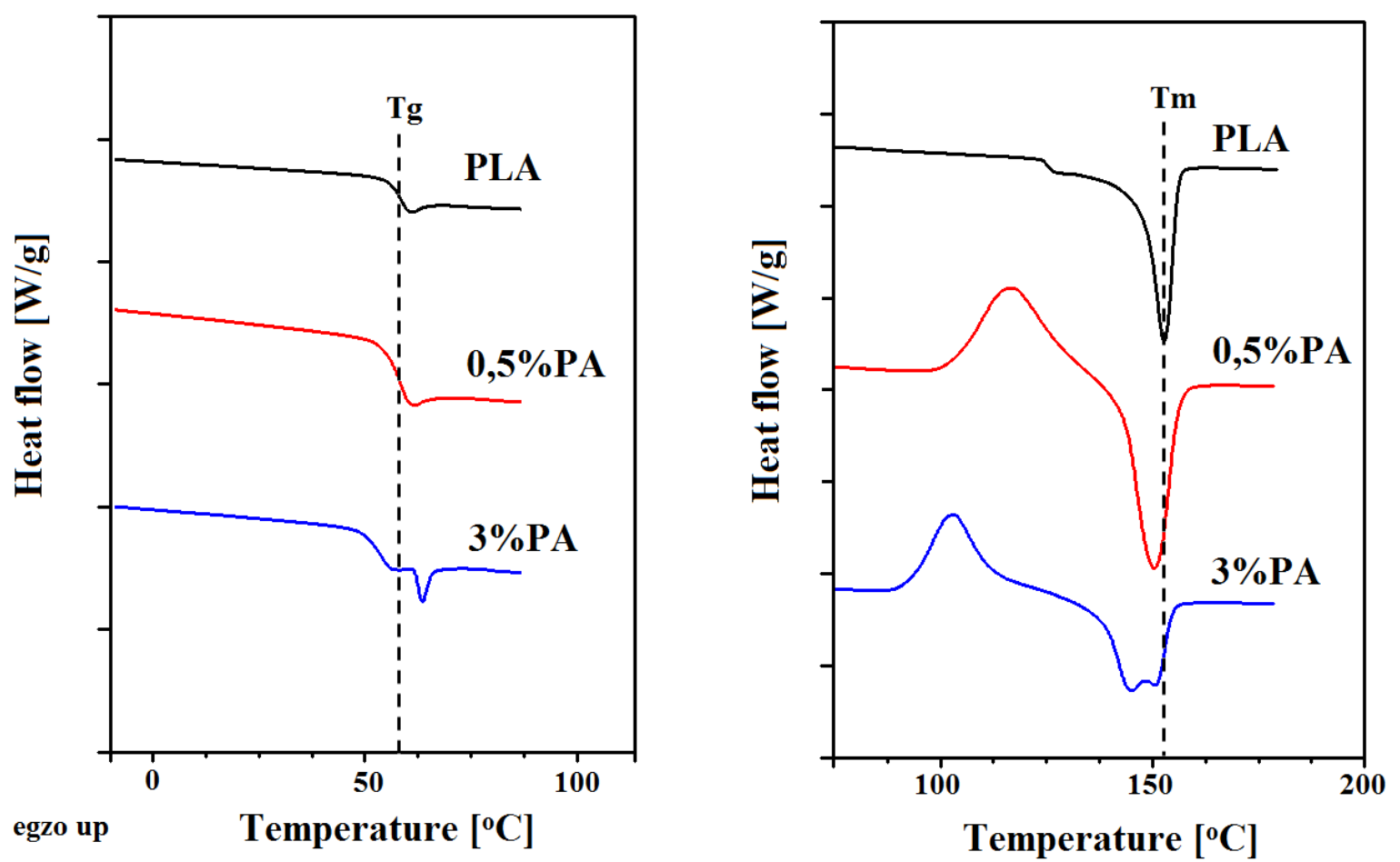

Fig.5. DSC thermograms of neat PLA and PLA modified palmitic acid in amount $0.5 \mathrm{wt} . \%$ and 3 wt.\%. 

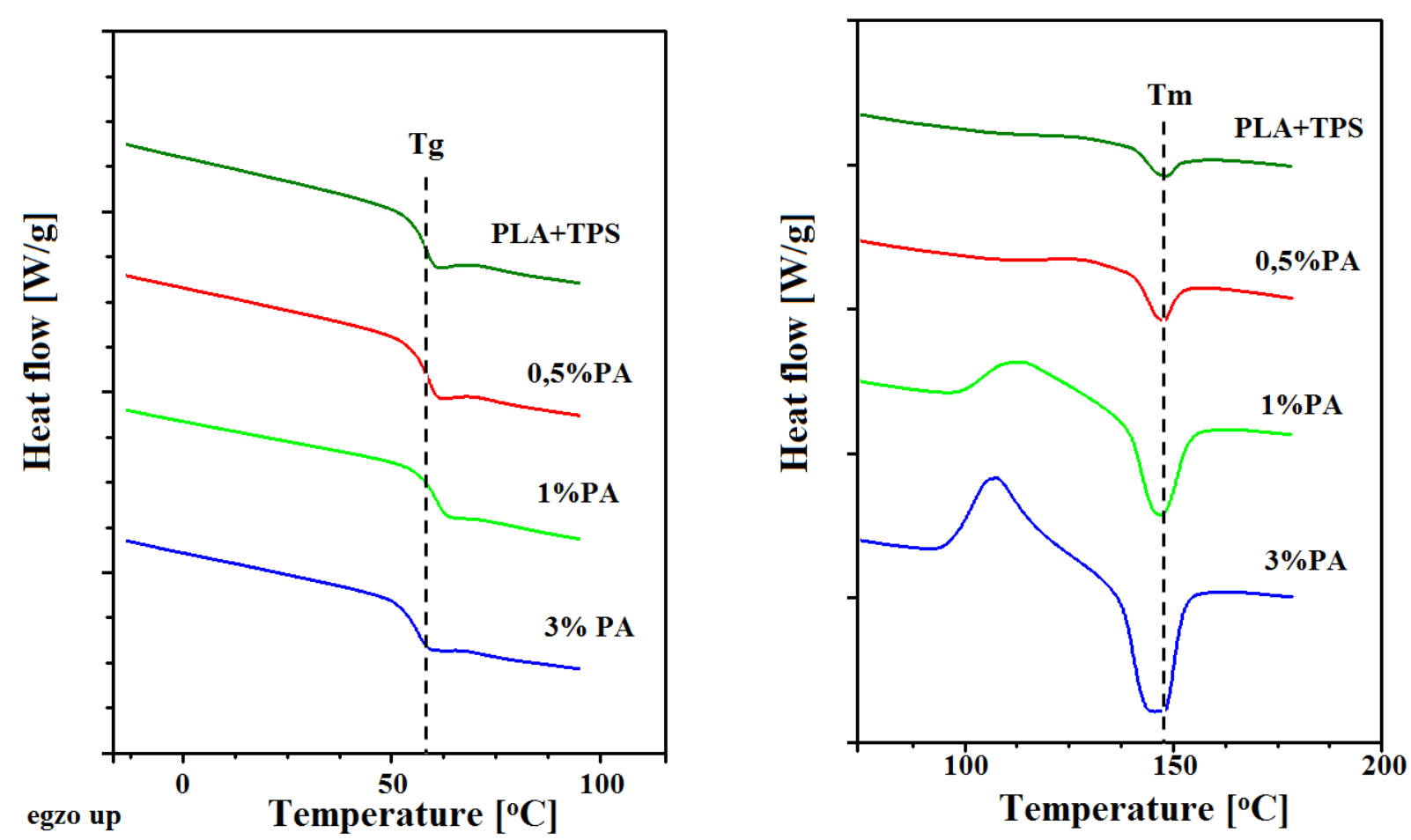

Fig.6. DSC thermograms of TPS/PLA (50/50) blends with different content of palmitic acid.

\section{Rheological properties}

TPS/PLA [50/50] blend itself had a MFR of $6.28 \mathrm{~g} / 10 \mathrm{~min}$ and a MVR of $5.22 \mathrm{~cm}^{3} / 10 \mathrm{~min}$. The use of palmitic acid in amount $0.5 \%$ and $1 \%$ in blend resulted in decreased of melt flow rate. A different situation was observed after adding $3 \%$ fatty acid to the blend. At that time, both index doubled (Table 2).

Table 2 Melt flow rate (MFR) and melt volume rate (MVR) of TPS/PLA blends modified by PA

\begin{tabular}{|c|c|c|c|c|}
\hline Temperature & \multicolumn{2}{|c|}{$\mathbf{1 9 0}^{\circ} \mathbf{C}$} & \multicolumn{2}{c|}{$\mathbf{2 1 0}^{\circ} \mathbf{C}$} \\
\hline Type of blend & $\begin{array}{c}\text { MFR, } \\
\mathrm{g} / 10 \mathrm{~min}\end{array}$ & $\begin{array}{c}\text { MVR, } \\
\mathrm{cm}^{3} / 10 \mathrm{~min}\end{array}$ & $\begin{array}{c}\text { MFR, } \\
\mathrm{g} / 10 \mathrm{~min}\end{array}$ & $\begin{array}{c}\text { MVR, } \\
\mathrm{cm}^{3} / 10 \mathrm{~min}\end{array}$ \\
\hline TPS/PLA (50/50) & 6,28 & 5,22 & 28,24 & 23,53 \\
\hline TPS/PLA (50/50) + 0,5\% PA & 5,00 & 4,21 & 21,79 & 18,28 \\
\hline TPS/PLA (50/50) + 1\% PA & 4,30 & 3,74 & 19,53 & 16,40 \\
\hline TPS/PLA (50/50) + 3\% PA & 16,25 & 13,68 & 92,67 & 81,01 \\
\hline
\end{tabular}

Fig. 7 shows the viscosity curves of TPS/PLA (50/50) blends in the double logarithmic system. The TPS/PLA blends exhibit the properties of pseudoplastic fluids. The real viscosity of the TPS/PLA blends decrease with an increasing temperature. Palmitic acid in addition in $0.5 \mathrm{wt} \%$ and $1 \mathrm{wt} . \%$ content in TPS/PLA blends slightly changes the viscosity as compared to the polymer composition plasticized only by glycerol. Then, the viscosity slightly increase or decrease depending on shear rate change. Overall, palmitic acid in amout $3 \mathrm{wt} . \%$ in blend can effectively reduce the melt viscosity. The same property was occured during the MFR measurements. This could be the result of the plasticization of the polylactide and its partially degradation into macromolecules with lower molecular weights, as indicates by the reduction of 
the melting point of PLA under influence of acid. The low viscosity of the TPS/PLA blend is favorable for injection process.
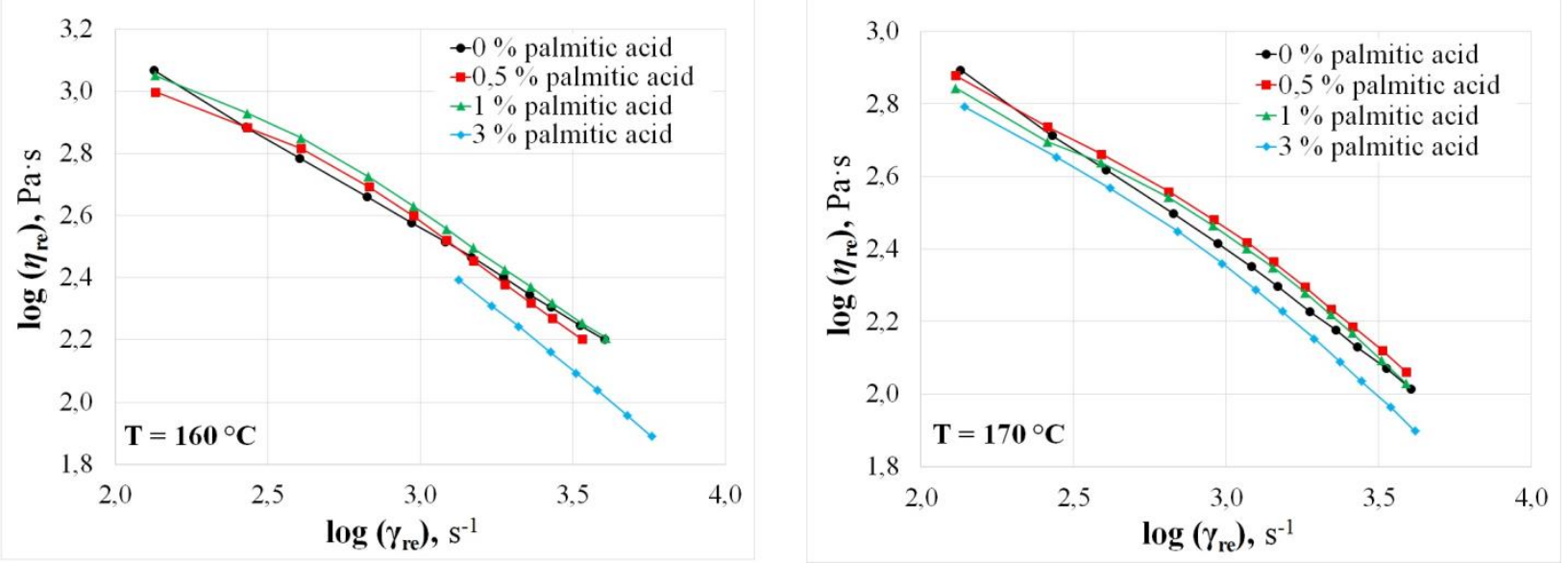

Fig.7. TPS/PLA composites capillary rheology test results.

\section{Conclusion}

TPS/PLA blends were produced by reactive extrusion with fatty acid as an additive. Fourier transform infrared spectroscopy (FTIR) suggests that palmitic acid partly reacts with hydroxyl group of the glycerol or starch by esterification reaction. The addition of palmitic acid to the TPS/PLA blend reduces the glass transition temperature of the polylactide and the melt viscosity. It can be concluded that palmitic acid has a plasticizing effect and at the same time facilitates processing as a lubricant. The viscosity results indicate that TPS/PLA composition can be further processed by extrusion and injection molding to obtain films or shapes.

\section{Acknowledgments}

This work was financially supported by The National Centre for Research and Development (LIDER X), grant number LIDER/36/0198/L-10/18/NCBR/2019 entitled: “The development of technology for obtaining the new biodegradable plastics based on thermoplastic starch for the films production".

\section{References}

[1] Averous, L. (2004). Biodegradable multiphase systems based on plasticized starch: a review. Journal of Macromolecular Science, Part C, 44(3), 231-274. https://doi.org/10.1081/MC200029326

[2] Huneault, M. A., Li, H. (2012). Preparation and properties of extruded thermoplastic starch/polymer blends. Journal of Applied Polymer Science, 126(S1), 96-108. https://doi.org/10.1002/app.36724

[3] Perez, S. Bertof, E. (2010). The molecular structures of starch components and their contribution to the architecture of starch granules: A comprehensive review. Starch Starke, 62(8), 389-420. https://doi.org/10.1002/star.201000013

[4] Rodriguez-Gonzalez, F. J., Ramsay, B. A., Favis, B. A. (2004). Rheological and thermal properties of thermoplastic starch with high glycerol content. Carbohydrate Polymers 58(2), 139-147. https://doi.org/10.1016/j.carbpol.2004.06.002

[5] Huneault, M. A., Li, H (2007). Morphology and properties of compatibilized polylactide/thermoplastic starch blends. Polymer 48(1), 270-280. https://doi:10.1016/j.polymer.2006.11.02 
[6] Auras, R., Harte, B., Selke, S. (2004). An Overview of Polylactides as Packaging Materials. Macromolecular Bioscience, 4(9), 835-864. https://doi.org/10.1002/mabi.200400043

[7] Kaseem, M., Hamad, K., Deri, F. (2012). Thermoplastic starch blends: A review of recent $\begin{array}{llll}\text { works. } & \text { Polymer Science } & \text { 165-176. }\end{array}$ https://doi.org/10.1134/S0965545X1202006X

[8] Olivato, J. B., Muller, C. M. O., Carvalho, G. M., Yamashita, F., Grossmann, M. V. E. (2014). Physical and structural characterisation of starch/polyester blends with tartaric acid. Materials Science and Engineering:C 39(1), 35-39. https://doi.org/10.1016/j.msec.2014.02.020

[9] Clasen, S. H., Muller, C. M. O., Pires, A. T. N. (2015). Maleic Anhydride as a Compatibilizer and Plasticizer in TPS/PLA Blends. Journal of the Brazilian Chemical Society 26(8), 15831590. http://dx.doi.org/10.5935/0103-5053.20150126

[10] Shi, R., Zhang, Z., Liu, Q., Han, Y., Zhang, L., Chen, D., Tian, W. (2007). Characterization of citric acid/glycerol co-plasticized thermoplastic starch prepared by melt blending. Carbohydrate Polymers 69(4), 748-755. http://dx.doi.org/10.1016/j.carbpol.2007.02.010 